\title{
BMJ The influence of time pressure on OPen adherence to guidelines in primary care: an experimental study
}

\author{
Evangelia Tsiga, ${ }^{1}$ Efharis Panagopoulou, ${ }^{1}$ Nick Sevdalis, ${ }^{2}$ Anthony Montgomery, ${ }^{3}$ \\ Alexios Benos ${ }^{1}$
}

To cite: Tsiga $\mathrm{E}$,

Panagopoulou E, Sevdalis N, et al. The influence of time pressure on adherence to guidelines in primary care: an experimental study. BMJ Open 2013;3:e002700. doi:10.1136/bmjopen-2013002700

- Prepublication history and additional material for this paper are available online. To view these files please visit the journal online (http://dx.doi.org/10.1136/ bmjopen-2013-002700).

Received 7 February 2013 Revised 8 March 2013 Accepted 13 March 2013

This final article is available for use under the terms of the Creative Commons Attribution Non-Commercial 2.0 Licence; see http://bmjopen.bmj.com

\section{ABSTRACT}

Objectives: Evidence from cognitive sciences has systematically shown that time pressure influences decision-making processes. However, very few studies have examined the role of time pressure on adherence to guidelines in clinical practice. The aim of this study was to examine the influence of time pressure on adherence to guidelines in primary care concerning: history taking, clinical examination and advice giving.

Design: A within-subjects experimental design was used.

Setting: Academic.

Participants: 34 general practitioners (GPs) were assigned to two experimental conditions (time pressure vs no time pressure) consecutively, and presented with two scenarios involving virus respiratory tract infections.

\section{Primary and secondary outcome measures:}

Outcome measures included adherence to guidelines on history taking, clinical examination and advice giving.

Results: Under time pressure, GPs asked significantly less questions concerning presenting symptoms, than the ones indicated by the guidelines, $(p=0.019)$, conducted a less-thorough clinical examination $(p=0.028)$, while they gave less advice on lifestyle $(p=0.05)$.

Conclusions: As time pressure increases as a result of high workload, there is a need to examine how adherence to guidelines is affected to safeguard patient's safety.

\section{INTRODUCTION}

Despite the fact that most medical decisions are taken in a context of pressure and uncertainty, time pressure has not been systematically addressed in relation to medical decision-making. As time pressure increases as a result of high workload and decreased resources, there is a need to examine how adherence to guidelines is affected.

Evidence from the cognitive sciences suggests that in situations with high time pressure or increased ambiguity, experts use

\section{ARTICLE SUMMARY}

Article focus

- Time pressure is a daily stressor in primary care and can significantly impact on quality of healthcare delivered.

- Very few studies have examined the role of time pressure on adherence to guidelines in clinical practice.

- The aim of this study was to examine the influence of time pressure on adherence to guidelines in primary care concerning: history taking, clinical examination and advice giving.

Key messages

- This study showed that under time pressure, adherence to guidelines concerning history taking and advice giving is compromised.

- Given the tendency towards a reduction of consultation times across Europe, it is important to safeguard the accuracy and efficiency of the diagnostic and treatment process, in order to reduce medical errors and increase patient safety.

Strengths and limitations of this study

- This is the first study using an experimental design to examine the role of time pressure on medical decision making in primary care.

- Decisions taken in everyday clinical practice are more complex, and influenced by a multitude of explicit and implicit factors.

intuitive decision-making strategies rather than structured approaches. ${ }^{12}$ It is therefore more likely for practicing physicians to rely on intuitive processes rather than evidence-based information, when formulating a decision under time pressure. In addition, evidence from psychological studies has systematically shown that time pressure influences risk assessment, ${ }^{3-5}$ the ability to learn ${ }^{6} 7$ and complex cognitive processing. ${ }^{8}$ Under time pressure, individuals process information faster, while use of analytic thinking is reduced. ${ }^{9}{ }^{10}$ Additionally, when faced with time-constraint conditions, individuals rely more often on emotional cues. ${ }^{11} 12$ 
Several studies have suggested that time pressure is one of the most important barriers to the use of evidence-based medicine in primary care. ${ }^{13} 14$ A systematic review on observational studies showed that longer consultations were associated with reduced medication prescriptions and increased advice on lifestyle changes. ${ }^{15}$ Similarly, Tamblyn et $a l^{16}$ showed that general practitioners (GPs) tend to prescribe inappropriate medications during shorter office visits. The study of Campbell et $a l^{17}$ showed that the most powerful predictor of the quality of management of chronic disease was the length of the consultation.

Although the above studies suggest a possible link between time pressure and evidence-based practice, their predictive validity is restricted by the fact that time pressure was assessed using self-reports or observational methods. In addition, shorter time visits were treated as synonymous to time pressure. To our knowledge, there is no experimental study on how time pressure impacts on physicians adherence to guidelines.

The aim of this study was to examine the influence of time pressure on GPs' adherence to guidelines concerning: history taking, clinical examination and advice giving.

\section{METHODS}

\section{Research design}

To increase power and decrease the error variance associated with differences among doctors, a within-subjects experimental design was used. Participants were assigned to two experimental conditions (time pressure vs no time pressure) consecutively. In each condition, participants were presented with two scenarios involving virus respiratory tract infections (RTIs). They were asked to respond to questions concerning medical history taking, clinical examination, referrals for lab tests, likelihood and certainty of final diagnosis, and treatment recommendations. In the experimental condition participants were given a specific time for each question. Participants in the control condition received no time constraints (figure 1). In order to avoid the effects of learning associated with within-subjects' designs, the counterbalancing technique was used to define the order of presentation of each condition.

\section{Clinical scenarios}

For the purposes of the study, four clinical scenarios concerning the diagnosis and treatment of virus RTIs were developed, using expert focus groups. All scenarios

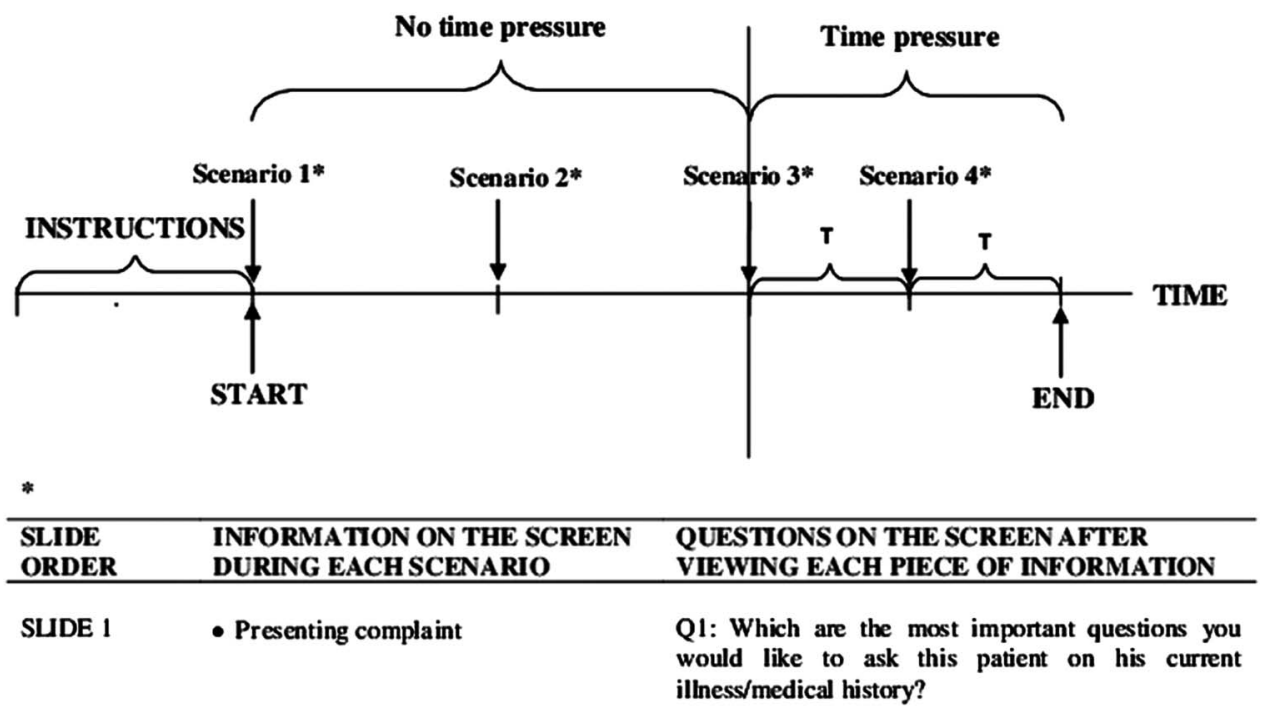

SUDE 2 - Presenting complaint
- Past Medical History

SUDE 3

SUDE 4

$\begin{array}{ll}\text { SUDE } 3 & \text { - Presenting complaint } \\ & \text { - Past Medical History } \\ & \text { - Clinical Examination } \\ \text { SUDE 4 } & \text { - Presenting complaint } \\ & \text { - Past Medical History } \\ & \text { - Clinical Examination } \\ & \text { - Laboratory Tests (Only for the UTI } \\ & \text { Scenario) }\end{array}$

Q2: Which are the most important signs that you want to look at in the physical examination?

Q3: Are there any other questions you would like to ask this patient?

Q4: Are there any diagnostic tests you would like to order for this patient?

Q5: According to the above information what is the most likely diagnosis for this patient?

Q6: How \% confident you feel about this diagnosis? Q7: What is your treatment plan for this patient?

Figure 1 Experimental design and procedure. 
were standardised in an initial pilot study in terms of the amount, and quality of information included (see online supplementary appendix I).

\section{Adherence to guidelines}

Participant responses were evaluated by two independent experts $(\mathrm{k}=0.89)$ based on the national guidelines set by the Greek Center for Disease Control and Prevention of Infectious Diseases. ${ }^{18} 19$

\section{Time pressure}

A pilot study involving 12 GPs was conducted, to define the response time for each question in the time pressure condition. ${ }^{320}$ Using the equation suggested by Ordonez and Benson ${ }^{3}$ the response time for each question $(\mathrm{T})$ was derived from the following equation: $T=T_{P}-S_{P}$ $\mathrm{TM}_{\mathrm{P}}$ corresponded to the mean response time for each question in the pilot study, while $\mathrm{SD}_{\mathrm{P}}$ to the mean $\mathrm{SD}$ for each question in the pilot study.

\section{Participants}

For a within-subjects two-group comparison where the difference is expected to be one $\mathrm{SD}$, and where $\alpha$ is 0.05 and power is 0.8 , the total sample size (per group) is expected to be 35 . Participants were recruited using an advertisement in the electronic newsletter of the General Practitioner Society of Thessaloniki, Greece. They were invited to participate in a study concerning medical decision making in general practice. Of the 198 GPs working in primary healthcare in the Thessaloniki metropolitan area, 73 responded to the advertisement and finally 34 participated in the study. In total, $38 \%$ of participants were male, while the mean age of participants was 38.41 years $(\mathrm{SD}=0.97)$. All participants participated in both experimental conditions.

\section{Procedure}

The study took place in a quiet, non-hospital-based setting. Participants were informed about the procedure and instructed to respond to the questions in the same way they would manage a patient in their daily practice. Demographic information was collected before the experiment. During the experiment, information on the presenting case appeared on the screen gradually followed by each question (figure 1). In the time pressure condition, a countdown clock was ticking on the screen. When the predefined time of a section was finished, the next information was presented independent of the performance of participants.

\section{Statistical analysis}

Results were analysed in two steps: first, $\chi^{2}$ test was used to compare the two experimental conditions in terms of correct responses (according to the guidelines) in each phase of the consultation (ie, medical history taking, clinical examination and treatment recommendations). The $\chi^{2}$ tests also compared the two conditions in terms of the correct diagnosis as well as confidence associated with the diagnostic decision.

Second, the number of correct responses in each phase were added for each participant to produce four continuous indicators, namely, number of questions asked on present illness (range 0-10), number of signs sought in clinical examination (range $0-6$ ), number of times lifestyle advice was given (range 0-3) and number of other necessary advice (range 0-2). Multivariate analysis of variance was used to compare the two conditions on the derived indicators.

\section{RESULTS}

Table 1 shows the differences between the two conditions in terms of correct responses as indicated by national guidelines. In specific, statistically significant differences between the two experimental conditions were observed on answers concerning consciousness disorders $(p<0.05)$, nervous system examination $(p<0.05)$, confidence in diagnosis $(\mathrm{p}<0.05)$ and smoking reduction advice $(\mathrm{p}<0.05)$, with all the above being lower under the time pressure condition.

In terms of the continuous indicators, under time pressure, GPs asked significantly less questions concerning presenting symptoms than the ones indicated by the guidelines $(\mathrm{F}=5.821, \mathrm{p}=0.019)$, conducted a less thorough clinical examination $(\mathrm{F}=5.024, \mathrm{p}=0.028)$, while they gave less advice on lifestyle $(\mathrm{F}=3.742, \mathrm{p}=0.05)$.

\section{DISCUSSION}

This study examined the influence of time pressure on compliance with national guidelines, and diagnostic certainty.

Overall, GPs' adherence to guidelines in the management of viral RTIs was low in both the experimental conditions regarding history taking, and advice concerning lifestyle. This is in agreement with previous studies indicating that evidence-based guidelines, are still not being adequately implemented in daily clinical practice. ${ }^{21} 22$ It is also related to the shift of modern medical practice towards more technocratic models of diagnosis and treatment. ${ }^{23} 24$

However, under time pressure, participants were asked less questions concerning symptoms of the presenting illness, and conducted less-thorough clinical examinations, as indicated by the national guidelines. For example, participants were less likely to ask about consciousness disorders during history taking, and less likely to examine the nervous system during the clinical examination, to exclude the possibility of meningitis. Since symptoms of viral respiratory infection (VRIs) can also be the presenting symptoms of both types of meningitis (bacterial and viral) the Greek Center for Disease Control and Prevention of Infectious Diseases, have included investigation of consciousness disorders, and nervous system examination as standard practice of the medical consultation. Failure to differentially diagnose meningitis can seriously 
Table 1 General practitioners' responses according to guidelines on respiratory tract infection scenarios*

\begin{tabular}{|c|c|c|c|}
\hline & Time pressure, no & Time pressure, yes & p Value \\
\hline \multicolumn{4}{|l|}{ Questions about present illness } \\
\hline Nasal congestion & $20.59 \%$ & $8.82 \%$ & 0.092 \\
\hline Fever & $55.88 \%$ & $51.47 \%$ & 0.679 \\
\hline Cough & $57.35 \%$ & $38.24 \%$ & 0.070 \\
\hline Breathlessness & $11.76 \%$ & $8.82 \%$ & 0.653 \\
\hline Chest pain & $1.47 \%$ & $1.47 \%$ & 1.000 \\
\hline Dizziness & $5.88 \%$ & $0.00 \%$ & 0.103 \\
\hline Consciousness disorders & $13.24 \%$ & $1.47 \%$ & 0.026 \\
\hline Intense/continuous vomiting & $13.24 \%$ & $7.35 \%$ & 0.341 \\
\hline Flu symptoms initially improved and returned or are getting & $7.35 \%$ & $1.47 \%$ & 0.325 \\
\hline \multicolumn{4}{|l|}{ worse during the last 2 days } \\
\hline \multicolumn{4}{|l|}{ Elements of physical examination } \\
\hline Temperature measurement & $41.18 \%$ & $35.29 \%$ & 0.600 \\
\hline Pharynx inspection & $89.71 \%$ & $85.29 \%$ & 0.517 \\
\hline Neck lymph node palpation & $27.94 \%$ & $13.24 \%$ & 0.063 \\
\hline Lung auscultation & $94.12 \%$ & $98.53 \%$ & 0.170 \\
\hline Heart auscultation & $29.41 \%$ & $25.00 \%$ & 0.660 \\
\hline Examination of nervous system & $82.35 \%$ & $41.18 \%$ & 0.000 \\
\hline \multicolumn{4}{|l|}{ Diagnosis } \\
\hline Respiratory viral infection & $98.53 \%$ & $98.53 \%$ & 1.000 \\
\hline Percentage ofconfidence on the diagnosis & $85.63 \%$ & $62.67 \%$ & 0.006 \\
\hline \multicolumn{4}{|l|}{ Medication } \\
\hline Antipyretics/painkillers & $89.71 \%$ & $77.94 \%$ & 0.113 \\
\hline \multicolumn{4}{|l|}{ Lifestyle treatment } \\
\hline Increase fluid intake & $64.71 \%$ & $47.06 \%$ & 0.115 \\
\hline Rest/stay at home & $47.06 \%$ & $38.24 \%$ & 0.424 \\
\hline Avoid smoking & $13.24 \%$ & $0.00 \%$ & 0.010 \\
\hline \multicolumn{4}{|l|}{ Other advice } \\
\hline Prevent transmission & $2.94 \%$ & $5.88 \%$ & 0.523 \\
\hline Re-examination, if symptoms persist or are getting worse & $52.94 \%$ & $52.94 \%$ & 1.000 \\
\hline \multicolumn{4}{|l|}{ Continuous indicators } \\
\hline Number of questions on present illness (mean) & 1.79 & 1.19 & 0.019 \\
\hline Number of signs in clinical examination (mean) & 5.69 & 4.48 & 0.028 \\
\hline Number of advice on lifestyle treatment used (mean) & 0.93 & 0.61 & 0.050 \\
\hline Number of other advice (mean) & 0.56 & 0.59 & 0.794 \\
\hline
\end{tabular}

compromise patient's safety. This finding suggests that under time pressure GPs were more likely to overlook lessfrequent conditions (availability heuristic). ${ }^{25}$ This tendency could have been exacerbated by the fact that the study was conducted during the time of influenza pandemic in Greece.

In addition, under time pressure participants were less compliant with guidelines on giving advice on lifestyle, especially, concerning smoking habits. This finding is in accordance with a study by Wilson et $a t^{26}$ showing that when the consultation time was increased, advice on smoking cessation, and alcohol reduction was more frequent. Failure to give advice on lifestyle changes compromises patient's recovery, especially, since evidence shows that in terms of treating VRIs lifestyle advice including smoking cessation, and increased fluid intake is the main treatment option.

Time pressure did not increase the ordering of diagnostic tests, a finding which is in contradiction with previous studies. $^{27} 28$ This could be because of the fact that in previous studies simulated patients were used instead of clinical scenarios, which increases the fear of malpractice and the tendency for defensive medicine. It could also be attributed to the content of the scenarios themselves which was consistent and therefore not requiring further testing.

In terms of diagnostic decisions no differences were observed between the two experimental conditions in terms of diagnostic accuracy. However, under time pressure participants felt less confident with their diagnosis. These findings are in accordance with studies showing that time pressure has a strong negative effect on information seeking, while diagnosis confidence was negatively related to the amount of information accessed in an experimental study in airplane pilots. $^{29}$

\section{LIMITATIONS}

This study used an experimental design based on clinical scenarios. However, decisions taken in everyday 
clinical practice are more complex, and influenced by a multitude of explicit and implicit factors. ${ }^{30}$ The use of simulated patients instead of clinical scenarios would have increased the ecological validity of the study. Another limitation concerns the nature of the scenarios used. RTIs represent routine clinical cases with limited management options. It is possible that the effect of time pressure on guidelines adherence and on diagnostic accuracy, would have been more pronounced in more clinical ambiguous situations. Further research, using a broader content of clinical cases is needed in order to investigate the effect of time pressure on GP's diagnostic accuracy and confidence. Given that guideline adherence is a complex psychological phenomenon shaped by the individual as well as by the context, future research should further examine the reasons of nonadherence to guidelines. For example, the concept rule violation could provide an interesting framework for examining the role of high expertise, lack of rule relevance or situation constraints on non-adherence in a time pressure situation. ${ }^{31} 32$

\section{CONCLUSIONS}

Time pressure is a daily stressor in primary care and can significantly impact on quality of healthcare delivered. $^{26} 28$ The present study showed that under time pressure, adherence to guidelines concerning history taking and advice giving is compromised. In an attempt to decrease the effects of time pressure on healthcare delivery, it has been suggested that consultation times should be increased, especially in primary care. However, despite the fact that there is a tendency to increase consultation time in some countries (ie, UK) ${ }^{33}$ this is not a standard practice mainly because of the associated financial cost. For example, in a study conducted by Deveugele $e t a l^{34}$ in primary care settings across six European countries, it was shown that the mean length of consultation decreased by about $6.5 \mathrm{~s}$ for every increase of 10 contact units a week in a doctor's workload. In addition, evidence on the effect of extending consultation times on health outcomes and patient satisfaction is limited and contradicting. A recent systematic review of Wilson and Childs $(2009)^{35}$ concluded that several aspects of doctors' behaviour (prescribing, referral, investigation and reconsultation) remain unchanged, despite major changes in appointment length. ${ }^{35}$ However, the small number of the studies included in the above review and their methodological limitations do not allow drawing a safe conclusion for the link between consultation times and quality of care. Consultation time may play a major core role in patients with psychological problems or comorbidities. ${ }^{36}$

Overall, simply increasing consultation times is not enough to decrease the effects of time pressure. This is also owing to the increased workload, and decreased resources which significantly increase the pressures of clinical practice in primary care. It is therefore important to safeguard the accuracy and efficiency of the diagnostic and treatment process, in order to reduce medical errors and increase patient's safety.

Contributors For the preparation of this paper, PE designed the study, supervised the data analysis and interpretation of results. SN wrote the first draft of the manuscript and conducted the statistical analysis. TE collected the data and revised the first draft of the manuscript. BA coordinated the study and the analysis of the outcomes. MA supervised the interpretation of results and edited the final draft and the language of the manuscript.

Funding This research received no specific grant from any funding agency in the public, commercial or not-for-profit sectors.

\section{Competing interests None.}

Provenance and peer review Not commissioned; externally peer reviewed. Data sharing statement No additional data are available.

\section{REFERENCES}

1. Dror I, Busemeyer J, Basola B. Decision making under time pressure: an independent test of sequential sampling models. Mem Cognit 1999;27:713-25.

2. Croskerry $P$. The cognitive imperative: thinking about how we think. Acad Emerg Med 2000;7:1223-31.

3. Ordonez L, Benson L. Decisions under time pressure: How time constraint affects risky decision making. Organ Behav Hum Decis Process 1997;71:121-40.

4. Ben Zur H, Breznitz JS. The effect of time pressure on risky choice behaviour. Acta Psychol 1981;47:89-104.

5. Kerstholt $\mathrm{JH}$. The effect of time pressure on decision-making behaviour in a dynamic task environment. Acta Psychol 1994;86:89-104.

6. DeDonno MA, Demaree HA. Perceived time pressure and the lowa Gambling Task. Judgm Decis Mak 2008;3:636-40.

7. Cella M, Dymond S, Cooper A, et al. Effects of decision-phase time constraints on emotion-based learning in the lowa Gambling Task. Brain Cogn 2007;64:164-9.

8. Van Harreveld F, Wagenmakers E, Van der Maas HL. The effects of time pressure on chess skill: an investigation into fast and slow processes underlying expert performance. Psychol Res 2007;71:591-7.

9. Benson L, Beach LR. The effects of time constraints on the prechoice screening of decision options. Organ Behav Hum Decis Process 1996;67:222-8.

10. Verplanken B. Need for cognition and external information search. $J$ Res Pers 1993;27:238-52.

11. Wright $P$. The harassed decision maker: time pressures, distractions, and the use of evidence. J Appl Psychol 1974;59:555-61.

12. Finucane $M L$, Alhakami $A$, Slovic $P$, et al. The affect heuristic on judgements on risks and benefits. J Behav Decis Mak2000;13:1-17.

13. McKenna HP, Ashton S, Keeney S. Barriers to evidence-based practice in primary care. J Adv Nurs 2004;45:178-89.

14. McColl A, Smith $H$, White $P$, et al. General practitioners' perceptions of the route to evidence based medicine: a questionnaire survey. BMJ 1998;316:7128.

15. Wilson $\mathrm{A}$, Childs $\mathrm{S}$. The relationship between consultation length, process and outcomes in general practice: a systematic review. $\mathrm{Br} \mathrm{J}$ Gen Pract 2002;52:1012-20.

16. Tamblyn R, Berkson L, Dauphinee D, et al. Unnecessary prescribing of NSAIDS and the management of NSAID-related gastropathy in medical practice. Ann Intern Med 1997;127:429-38.

17. Campbell SM, Hann M, Hacker J, et al. Identifying predictors of high quality care in English general practice: observational study. BMJ 2001;323:1-6.

18. Center for Disease Control and Prevention. Scientific committee for hospital infections. Guidelines for diagnosis and empirical treatment of infectious diseases. Athens: Focus on Health Ltd, 2007:4-11.

19. Center for Disease Control and Prevention. Greek Ministry of Health and Public Solidarity. Current clinical guidelines for the treatment of H1N1 clinical cases in health care services. http://www.keelpno.gr/

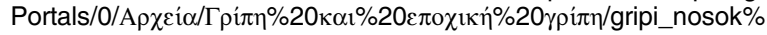
5B1\%5D.pdf (accessed 6 Sep 2012).

20. Benson L, Svenson O. Post decision consolidation following the debriefing of subjects about experimental manipulations affecting their prior decisions. Psychol Res Bull 1993;32:1-13. 
21. Cleland JG, Cohen-Solal A, Aguilar JC, et al. Management of heart failure in primary care (the IMPROVEMENT of Heart Failure Programme): an international survey. Lancet 2002;360:1631-9.

22. Steel N, Bachmann M, Maisey S, et al. Self reported receipt of care consistent with 32 quality indicators: national population survey of adults aged 50 or more in England. BMJ 2008;337:957.

23. Hampton R, Harrison MJ, Mitchel JR, et al. Relative contributions of history-taking, physical examination, and laboratory investigation to diagnosis and management of medical outpatients. BMJ 1975;2:486-9.

24. Davis-Floyd R. The technocratic, humanistic, and holistic paradigms of childbirth. Int J Gynaecol Obstet 2001;75 (Suppl 1):5-23.

25. Ely JW, Graber ML, Croskerry P. Checklists to reduce diagnostic errors. Acad Med 2011;86:307-13.

26. Wilson $\mathrm{A}, \mathrm{McD}$ Donald $\mathrm{P}$, Haynes $\mathrm{L}$, et al. Health promotion in the general practice consultation: a minute makes a difference. $B M J$ 1992;304:227-30.

27. Van der Weijden T, Van Bokhoven MA, Dinant G, et al. Understanding laboratory testing in diagnostic uncertainty: a qualitative study in general practice. Br J of Gen Pract 2002;52:974-80.

28. Whiting $\mathrm{P}$, Toerien M, De Salis I, et al. A review identifies and classifies reasons for ordering diagnostic tests. J Clin Epidemiol 2007;60:981-9.
29. Mosier KL, Sethi N, McCauley S, et al. What you don't know can hurt you: factors impacting diagnosis in the automated cockpit. Hum Factors 2007;49:300-10.

30. Beullens J, Rethans JJ, Goedhuys J, et al. The use of standardized patients in research in general practice. Fam Pract 1997;14:58-62.

31. Lawton R. Not working to rule: understanding procedural violations at work. Saf Sci 1998;28:77-95.

32. Reason J, Parker D, Lawton R. Organizational controls and safety: the variety of rule related behavior. J Occup Organ Psychol 1998;71:289-304.

33. DOH 1998. Department of Health. Review body on doctors' and dentists' remuneration report. Appendix E (pamphlet). London: The Stationery Office, 1998.

34. Deveugele M, Derese A, van den BrinkMuinen A, et al. Consultation length in general practice: cross sectional study in six European countries. BMJ 2002;31:325-472.

35. Wilson $A D$, Childs $S$. Effects of interventions aimed at changing the length of primary care physicians' consultation. Cochrane Database Syst Rev 2006;1:1-18.

36. Hutton C, Gunn J. Do longer consultations improve the management of psychological problems in general practice? A systematic literature review. BMC Health Serv Res 2006;7:71 